\title{
JUURNAL.RU
}

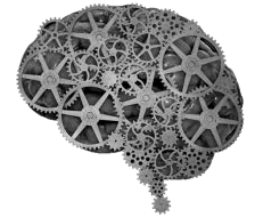

COMPANY GROUP "INTELLEKT"

\author{
Винокуров С.И. ${ }^{1}$, Винокурова М.В. ${ }^{2}$ \\ ${ }^{1}$ Иркутский государственный аграрный университет имени А.А. Ежевского \\ ${ }^{2}$ Байкальский государственный университет \\ Иркутск, Россия
}

doi: 10.18411/lj2016-5-1-02

\section{Тенденции развития компаний в пищевой промышленности}

Аннотация: В проведенном исследовании автором были выявлены негативные тенденции, такие как высокая доля продукции иностранных производителей, низкая эффективность переработки сырья пищевыми компаниями и т.п., которые сказываются на продовольственной безопасности страны. Подъем отрасли пищевой промышленности в России возможен за счет преодоления негативных тенденции и развития крупных компаний в отрасли, использующих стратегии интегрированного и диверсифицированного роста.

Ключевые слова: управление, тенденции, интеграция, диверсификация, пищевая промышленность.

Низкие темпы развития компаний в пищевой промышленности, не позволяющие обеспечивать население качественными и натуральными продуктами питания.

На сегодняшний момент специальная литература и проводимые исследования касающиеся вопросов развития компаний в пищевой промышленности в России насчитывает небольшое количество источников. При изучении этих вопросов можно выделить работы следующих авторов Е. Л. Дугиной, М. А. Тараканова, Н. В. Сироткиной, И. П. Богомоловой, Е. А. Баевой, В. Н. Ивановой, С. Н. Серегина, В. С. Гринько, С. Цухло, М. Ф. Тяпкиной, Н. Ю. Сухиной, И. Ю. Немцовой, Н. В. Сироткиной и др. 
Импортозамещение в пищевой и смежных с ней отраслях в целях обеспечения продовольственной безопасности России.

Цель статьи - выявить современные тенденции развития хозяйствующих субъектов в отрасли.

В современном обществе наблюдаются несколько тенденций, определяющих стратегическое развитие компаний. Это усиление глобализации на рынке, развитие информационных технологий, повышение требований клиентов, инновационный путь развития производства, усиление внимания к вопросам охраны окружающей среды, ориентация клиентов на здоровый образ жизни. Такие тенденции позволяют формировать крупным компаниям такие стратегии, которые стимулируют развитие конкуренции и рост эффективности деятельности отдельных предприятий и отраслей, а также оптимального сочетания различных секторов экономики. По нашему мнению, основными современными тенденциями в отрасли пищевой промышленности являются:

1. Развитие процуессов интеграцฺии предприятий пищевой промышленности с сельскохозяйственными организацуиям.

Компании пищевой отрасли выстраивают свои технологические цепочки таким образом, чтобы контролировать весь производственный процесс, начиная с выращивания продукции растениеводства и животноводства, и заканчивая переработкой, дистрибуцией и продажей через розничную сеть [1, С. 37].

Объединению сельского хозяйства и пищевой промышленности способствуют и такие факторы как, возможность более рационального использования трудовых ресурсов в течение года, увеличению уровня товарности сельскохозяйственного производства, более быстрая переработка сырья с ограниченным сроком использования, что в свою очередь влияет на улучшение качества производимой продукции.

2. Высокая доля продукичи иностранных производителей.

Масштабы контроля рынка подразделениями иностранных корпораций в некоторых отраслях очень значительны: более 90\% рынка плодовоовощной 
консервации, более $80 \%$ рынка пивоварения, почти $80 \%$ рынка замороженных овощей и фруктов, более $70 \%$ рынка соковой продукции, около $60 \%$ рынка переработки молока [2, С. 288]. Отечественные производители сохраняют лидерство на рынках скоропортящихся натуральных продуктах, например мясопереработки и хлебобулочных изделий. Значительная часть пищевой продукции не связана с российской сырьевой базой, например продукция таких производители безалкогольных напитков и питьевой воды, как «Coca-Cola» и «PepsiCo», пива («Carlsberg», «SunBrewing» и др.), йогуртов и плавленых сыров («Ehrmann», «Hochland», «Danone», «Lactalis» и др.), кондитерских изделий («Nestle», «Mars», «KraftFoods» и др.), маргарина, майонеза, кетчупа («Unilever»). Зарубежные компании нацелены на высокорентабельный сегмент рынка пищевых продуктов с низкой долей натурального сырья, где нет зависимости производства от нестабильности свойств такого рода сырья и цен на него.

В этой связи низкая конкурентоспособность отечественной продукции связана с рядом проблем, которые будут описаны ниже. Многие отечественные компании пищевой промышленности России ориентированы на производство продукции с высокой долей натурального сырья для удовлетворения существующих потребностей населения. Однако такие продукты являются менее конкурентными для потребителей по цене. Потребитель выбирает товар лучший по соотношению цена-качество, поэтому для компаний пищевой промышленности актуальны вопросы изменения своей продукции для удовлетворения интересов потребителей не только с позиции качества, но и с позиции цены.

3. Рост инвестиционного потенциала пищевой промышленности при снижении инвестиционной привлекательности для зарубежных инвесторов. В последние годы российская пищевая промышленность демонстрирует небольшой, но устойчивый рост. Рынок пищевых продуктов имеет незаполненные ниши, поэтому пищевая отрасль является привлекательной для 
инвесторов, которые стремятся заполнить свободные ниши в быстрорастущих сегментах (молочные, диетические продукты и детское питание, переработка мяса, овощей и фруктов).

Эффективность инвестиций в пищевую промышленность определяется выгодностью капитальных вложений и скоростью получения эффектов от этих вложений. Темпы привлечения инвестиций в основной капитал пищевой промышленности выше относительно других отраслей промышленности, что подтверждает факт инвестиционной привлекательности отрасли и дает основания говорить о перспективности ее будущего развития. Практически по всем группам пищевых продуктов за исключением овощей, картофеля и яйца производство не покрывает уровень потребления, при этом потребление не соответствует существующим нормам потребления на одного человека. Соответственно существуют незанятые рыночные ниши, которые можно заполнить. В последние годы до применения санкций в отношении Российских компаний и мер ответных санкций со стороны России наиболее привлекательной с точки зрения иностранных инвестиций являлась пищевая промышленность. Это вызвано стремлением иностранных компаний увеличить свое присутствие на российском продовольственном рынке из-за ухудшения эффективности импорта своей готовой продукции и тенденции снижения спроса на продукцию зарубежного производства вследствие смены потребительских предпочтений.

Важно отметить, что инвестиционный потенциал пищевой промышленности не имеет возможности на данный момент быть покрытым инвестициями российских компаний, поэтому рост и развитие в ближайшее время стоит ожидать в отрасли только за счет развития крупных компаний, имеющих собственные средства, которые можно реинвестировать в собственное производство.

4. Ориентаџฺия компаний пищуевой отрасли на внутренний, преимущуественно региональнылй рынок. Опыт развития компаний пищевой 
отрасли развитых стран, таких как США, Германия, Франция, Италия и др. показывает, что первоначально они ориентировались на внутренний рынок и только при исчерпании потенциала внутреннего рынка для компаний они переориентировались на внешние рынки. Российский рынок пищевых продуктов не обеспечивает минимальный уровень потребления практически по всем основным продуктам питания. Российские производители пищевой продукции продают свою продукцию преимущественно в рамках своего региона, где наблюдается доминирование продукции местных производителей. Это и особенность их развития, но и в какой-то мере угроза со стороны конкурентов, а также можно говорить, что это и возможности дальнейшего роста этих компаний.

На данный момент одной из самых главных проблем сельскохозяйственных предприятий является реализация готовой продукции. Продукция пищевых производств имеет ограниченные и специфичные сроки хранения, поэтому существующие каналы сбыта зачастую имеют низкую эффективность при изменении объемов производства, отсюда сами производители несут потери, и поэтому ищут пути выхода из сложившейся ситуации. Это является одним из направлений дальнейшего развития крупных компаний в данной отрасли, требующего отдельного внимания менеджмента компании при разработке стратегии.

Заявленный правительством курс на импортозамещение дает возможность получения поддержки государства на развитие российского производства пищевой продукции и, возможно, даст толчок для выхода компаниям за пределы регионального рынка.

5. Снижение платежеспособного потребительского спроса. В условиях кризиса и стагнации экономики, по оценкам экспертов, пищевую отрасль также ждет снижение платежеспособного потребительского спроса на продукцию и снижение объемов потребления по основным видам продуктов, а также изменение приоритетов в потреблении в сторону более дешевых заменителей. 
Это подтверждается отсутствием позитивной динамики в потреблении продуктов питания данными Росстата о динамике экономических индикаторов РФ, указывающих на наличие рисков недооцененности масштабов падения покупательной способности. Поскольку потребление продуктов имеет тенденцию к снижению уже давно и не объясняется временной корректировкой, а наоборот говорит о реальном снижении платежеспособного спроса населения.

б.Низкая эффрективность переработки сырья для пищевой промышленности. В отрасли пищевой промышленности низкий коэффициент обновления оборудования (5-7\%). Это связано с отсутствием должного внимания к пищевой промышленности со стороны государства. На изношенном оборудовании с низкой производительностью не возможно производить качественные и конкурентоспособные продукты питания. Поэтому значительная часть сельскохозяйственного сырья и производимых ресурсов для переработки, используется неэффективно. [3, С. 16]

7. Недозагруженность собственных мощзностей. По материалам опроса 200 предприятий и отраслей РФ, проводимым сотрудниками центра по изучению переходной экономики Института мировой экономики и международных отношений РАН, загруженность производственных мощностей в пищевой промышленности составляет около 80\%. Низкая загрузка мощностей отмечается в сельскохозяйственном производстве - около 70\%. Неэффективная загрузка производственных мощностей не позволяет крупным компаниям отрасли сконцентрировать финансовые ресурсы для осуществления модернизации отрасли, снижения издержек и увеличения эффективности собственного производства [4, С. 65].Существуют отрасли экономики, в которых наблюдается высокий объем производства продукции и высокая капиталоемкость производства, а также высокая фондовооруженность. В них сосредоточен в основном крупный бизнес. Это металлургическая промышленность, автомобильная, фармацевтическая, химическая, большинство предприятий добывающих отраслей, пищевая и сельское хозяйство. В этих 
отраслях сосредоточены интегрировано-диверсифицированные компании $[1, \mathrm{C}$. 39].

Крупные зарубежные компании, действующие в рамках одной отрасли и имеющие в своей структуре интегрированные подразделения, либо обладающие подразделениями не связанными с основной деятельностью, стремятся от этих подразделений избавиться. Либо перестраивают вектор своего развития на загрузку заказами уже имеющихся мощностей подразделений с целью повышения эффективности их деятельности.

Для обеспечения полной загрузки необходимо выйти за рамки отдельной компании, сконструировать цепочки, схемы, сети производства новых продуктов и услуг, новой стоимости, имеющие сетевой, открытый характер. Большинство ресурсов, требуемых для реализации этой загрузки, могут находиться вне отдельного предприятия и зоны его административного влияния. Поскольку у отдельной компании недостаточно административного влияния для объединения всех необходимых ресурсов, находящихся у разных собственников, при создании альянса придется иметь дело не с самими ресурсами (станками, складскими помещениями, транспортными сетями), а с собственниками этих ресурсов. Они имеют свою идентичность и систему ценностей, интересы, предпочтения, планы, и со своей стороны могут точно так же встраивать другие компании в собственные планы. Следовательно, стратегический альянс должен иметь субъектный, рефлексивный характер. Необходимо учитывать интересы партнеров. Для этого необходима концепция создания работающей технологии, которая сможет производить предпринимательские проекты. Современные проектные стандарты больше имеют дело с ресурсами, a не с их собственниками.

8. Потребление экологически чистой $u$ натуральной продукции отечественных производителей $и$ снижение негативного воздействия на окружающую среду. Современные тенденции в потребительских предпочтениях заключаются в потреблении натуральных и экологических пищевых продуктов. 
Отставание в отечественных компаний пищевой отрасли от иностранных компаний в уровне внедрения научных разработок для пищевых производств при имеющихся недостатках оказывает положительное воздействие в том, что крупные отечественные компании используют натуральное сырье для дальнейшей переработки. Также, на наш взгляд, важное значение имеет необходимость эффективного использования отходов пищевых и перерабатывающих организаций для производства энергоресурсов и продуктов для вторичной переработки, которое обеспечит повышение эффективности производства и снизит вредное воздействие организаций на окружающую среду.

Выводы. Выявленные тенденции развития пищевой промышленности России подтверждают необходимость развития компаний в отрасли при помощи конкурентных преимуществ более высокого порядка. Социальная значимость, большая потенциальная емкость российского продовольственного рынка, привлекательность пищевой промышленности для инвесторов делают актуальными вопросы развития компаний отрасли и повышения их конкурентоспособности.

В условиях усиления глобальной конкуренции могут развиваться, и расти компании, обладающих уникальными производствами $\quad$ и $\quad$ наилучшей эффективностью деятельности. Для этого в них должны постоянно проводиться изменения, как самих бизнес-процессов, так и организации их проведения. Так, в развитых странах мира около 3/4 прироста валового внутреннего продукта обеспечивается инновациями. Лидерами в инновационной деятельности, как правило, выступают крупные компании, имеющие достаточное количество ресурсов для поддержания инновационного развития компании.

Исходя из этого проблемы, определяемые основными социальноэкономическими, научно-техническими и экологическими задачами человечества, могут решаться при развитии таких компаний, которые являются локомотивом развития в обществе. 
Поэтому внимание государства должно быть направлено на стимулирование развития крупных и средних компаний, важных, с точки зрения государственной безопасности, которые в своей деятельности основываются на инновациях и имеют большие возможности для их внедрения в собственное производство. Компании пищевой отрасли являются стратегически важными для государства с точки зрения продовольственной безопасности страны наравне с компаниями оборонной промышленности.

Россия, как и другие страны мирового сообщества должны решать такие глобальные проблемы как, продовольственная проблема, проблемы связанные с энергосбережением, проблема экологии и устойчивого развития, проблема бедности, демографическая проблема, проблема развития человеческого потенциала, проблема обеспечения человеческой безопасности и т.д. Все вышеперечисленные проблемы государство должно решать при тесном взаимодействии с крупными компаниями, т.к. от их развития зависит развитие экономики всей страны.

\section{S. I. Vinokurov, M. V. Vinokurova \\ Irkutsk state agricultural university of a name A.A.Ezhevsk Baikal State University \\ Trends of development companies in the food industry}

Summary: In the author research negative trends, such as a high share of the foreign producers production, low efficiency of processing of raw materials by the food companies, etc. which affect food security of the country have been revealed. The food industry in Russia growth is possible due to overcoming negative tendencies and developments of the large companies using strategy of the integrated and diversified growth.

Keywords: management, tendencies, integration, diversification, food industry. 


\section{Литература:}

1. Винокуров С. И. Диверсификация и вертикальная интеграция как способы развития компаний пищевой промышленности // Развитие экономических и межотраслевых наук в XXI веке / XVII международ. науч.-практ. конф., 06-07 ноября 2015 г. - Новосибирск, - 2015. № 10 (17). - С. 35-39.

2. Гладышева, А. А. Роль неоднородности и взаимного влияния ре-гионов России в распределении прямых иностранных инвестиций в пищевую отрасль [Текст] / А. А. Гладышева, Т. А. Ратникова // Экономический журнал ВШЭ. - 2014. - № 2. - С. 285-327.

3. 3.Ефимов В. С. Промышленная политика и возможности импортозамещения для Сибири и Дальнего Востока / В. С. Ефимов, А. В. Ефимов // ЭКО. - 2015. - № 2. - С. 14-20.

4. Тараканов M. А. Пищевая промышленность Иркутской области: проблемы, перспективы // Экономист. - 2014. - №6. - С. 61-70.

5. Цухло С. Как победить засилье импорта // Эксперт. - 2015. - №12 (938). 